\title{
Unified Modelling and Theoretical Analysis of Various Refining Processes*
}

\author{
By Shigeo ASAI** and Iwao MUCHI**
}

\section{Synopsis}

In the case of the refining processes in which oxygen participates, the transitional variations in each concentration of the reaction components in molten steel may be determined on the basis of the balances of the following two driving forces. Namely, the one has an essential tendency allowing the system to approach to the equilibrium, and the other caused by oxygen supplied into $a$ bath acts in the opposite direction and has a tendency to keep the system away from the equilibrium.

Based on these driving forces, a simplified model involving important characteristic factors $A$ and $B$ is proposed in this paper. The effects of the feeding rate of available oxygen, the degree of mixing of molten steel, the temperature of molten steel and the partial pressure of carbon monoxide on the transitional variations of process variables are definitely controlled by these factors.

The experimental data obtained by the other investigators in regards to the oxidation reactions in the molten steel of $\mathrm{Fe}-\mathrm{Si}, \mathrm{Fe}-\mathrm{C}-\mathrm{Si}, \mathrm{Fe}-\mathrm{C}-$ $\mathrm{Cr}$ and $\mathrm{Fe}-\mathrm{Si}-\mathrm{Mn}$ systems, are analysed theoretically with the aid of the model.

From the comparison between the experimental data obtained in LD converter and those in crucible, it has been well known hitherto that there exists a difference in the proceeding sequence of the oxidation of silicon and the decarburization, and the difference is quantitatively clarified by the use of the model.

Furthermore, it is found that the model can be applied to the reactioncontrolling processes such as the reaction of carbon and oxygen in molten iron and the simultaneous reaction between the molten iron and the mixture of $\mathrm{CO}$ and $\mathrm{CO}_{2}$.

\section{Introduction}

Concerning the refining processes, there are a large number of studies on the oxidation reactions taking place in molten steel. However, the following differences have not been sufficiently analysed yet; namely, the difference in the proceeding sequence of the oxidation of silicon and the decarburization which is widely known from the comparison between the results observed in LD converter and those in crucible, the difference in the oxygen level of molten steel among the experimental data obtained by many investigators in open hearth, LD converter and crucible and the difference in the oxygen level caused by the alternations of the feeding rate of oxygen in LD converter.

It may be considered that the oxidation reactions taking place in molten steel have connection with each other through oxygen in the steel bath as a medium of the reactions, and that the transitional variations in each concentration of the components taking part in the oxidation reactions in molten steel may be determined from the balance of the following two driving forces. Namely, the one has an essential tendency allowing the system to approach to the equilibrium, and the other caused by oxygen supplied into a bath acts in the opposite direction and has a tendency to keep the system away from the equilibrium.

In this paper, on the basis of these two driving forces, a simplified model is proposed by taking account of the effects of the feeding rate of available oxygen, the degree of mixing of molten steel, the temperature of molten steel and the partial pressure of carbon monoxide on the transitional variations of process variables. By the use of this model, the experimental data obtained by the other investigators concerning the differences in the proceeding sequence of oxidation and in the oxygen level are explained theoretically.

Furthermore, the applicability of the model is examined for the case of the reaction-controlling processes taking place in molten iron.

\section{Theoretical Analysis}

\section{Concentration Relation of Carbon and Oxygen}

From the experimental data obtained by the other investigators in LD converter, crucible and open hearth, it can be found that the points representing the relations between the concentrations of carbon and oxygen in molten steel distribute at the upper part than the equilibrium line of $\underline{\mathrm{C}}$ to $\underline{\mathrm{O}}$ expressed on a graph paper of rectangular coordinates.

These relations are illustrated in Fig. I (a). The solid line (1) represents the equilibrium line of $\underline{C}$ to O and the dotted line (2) represents the actual trajectory which moves from the high carbon concentration to the low one during the blowing process.

In the decarburization, the greater portion of oxygen absorbed in molten steel may be consumed by the reaction and the rest of it may be accumulated in the bulk of molten steel. Taking the material balance for oxygen at the elapsed time, $\Theta$, Eq. (1) can be obtained:

$$
\int_{0}^{\Theta}(S / W) d \Theta=\left(C_{\mathrm{O}}-C_{i, \mathrm{O}}\right)+\left(M_{\mathrm{O}} / M_{\mathrm{C}}\right)\left(C_{i, \mathrm{C}}-C_{\mathrm{C}}\right)
$$

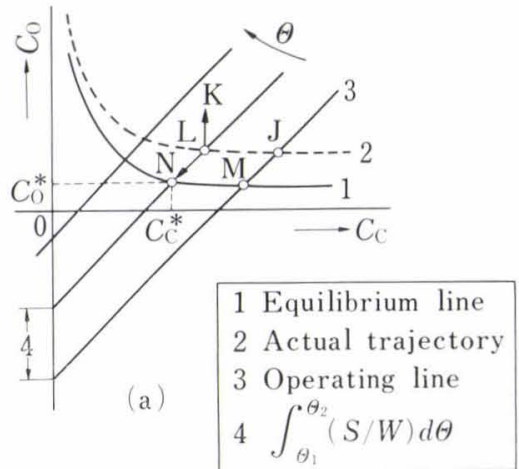

Fig. 1(a) Relations between the concentrations of carbon and oxygen in molten steel and operating line

* Originally published in Tetsu-to-Hagané, 58 (1972), 675, and S 53, in Japanese. English version received July 25 , 1973.

** Department of Iron and Steel Engineering, Nagoya University, Furo-cho, Chikusa-ku, Nagoya 464. 


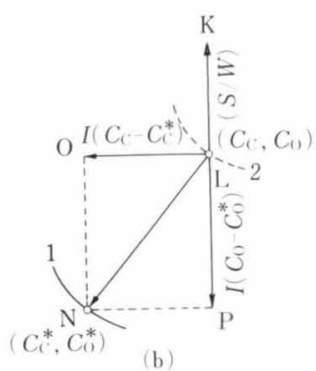

(b)
Fig.1 (b)

Illustration of the driving forces
As shown in Fig. 1, Eq. (1) is presented by a group of operating lines which move in the direction of the arrow as the blowing process proceeds. Now, if the feeding of oxygen were ceased at the time when the concentrations of carbon and oxygen are shown by the point $\mathrm{J}$, then the point $\mathrm{J}$ would move to the point $\mathrm{M}$ along the path of the operating line (3), and finally the system would reach its equilibrium state at the point M. Since the equilibrium relation between the concentrations of carbon and oxygen can be given by Eq. (2), the intersection of the operating and equilibrium lines can be determined from Eqs. (1) and (2) as a function of the elapsed time, the temperature of molten steel and the partial pressure of carbon monoxide.

$$
C_{\mathrm{O}} \cdot C_{\mathrm{C}}=p_{\mathrm{CO}} / K(T)
$$

If the concentrations of carbon and oxygen are shown by the point $\mathrm{L}$ and the intersection of the operating and equilibrium lines is given by the point $\mathrm{N}$ which has the coordinates $\left(C_{\mathrm{c}}^{*}, C_{0}^{*}\right)$, then the system would move from the point $\mathrm{L}$ to the point $\mathrm{N}$ by the action of the driving force, $\overrightarrow{\mathrm{LN}}$. Fig. $\mathrm{l}(\mathrm{b})$ is a magnified figure of Fig. 1 (a). As shown in Fig. 1 (b), the driving force, $\overrightarrow{\mathrm{LN}}$, may be resolved into the two driving forces of $\overrightarrow{\mathrm{LO}}$ and $\overrightarrow{\mathrm{LP}}$. The smaller the resistances with respect to the reaction and the mass transfer which takes place during the movement from the point $\mathrm{L}$ to the point $\mathrm{N}$ are, the more rapidly the system arrives at the point $\mathrm{N}$.

When oxygen is absorbed into molten steel, the driving force corresponding to the amount of $(S / W)$ in the direction of $\overrightarrow{\mathrm{LK}}$ against $\overrightarrow{\mathrm{LP}}$ acts upon the system at the point L. As shown by the dotted line in Fig. 1, the concentration relation of $\underline{\mathrm{C}}$ and $\underline{\mathrm{O}}$ which may be obtained from the practical operations can be determined from the balance of these two driving forces. From the idea mentioned above, the difference in the oxygen level among the experimental data obtained in open-hearth furnace, LD converter and crucible can be explained as follows. Inferring the experimental data ${ }^{1,2}$ reported hitherto, the largest gap between the experimental data and the equilibrium line can be seen in open-hearth furnace, and the larger one can be found in LD converter. The data obtained in crucible almost coincide with the equilibrium line.

In open-hearth furnace the value of the feeding rate of oxygen is so small that the driving force, $\overrightarrow{\mathrm{LK}}$, becomes small. On the other hand, as the mixing of molten steel may be very weak, the driving force, $\overrightarrow{\mathrm{LN}}$, becomes smaller. Hence, it may be thought from the balance of these driving forces that the largest deviation from the equilibrium line is produced in the case of open-hearth furnace.

The driving force, $\overrightarrow{\mathrm{LK}}$, in LD converter becomes large, since the feeding rate of oxygen is very large. On the other hand, as the mixing of molten steel caused by the oxygen jet is very violent, the driving force, $\overrightarrow{\mathrm{LN}}$, becomes larger. From the balance of these driving forces, it may be inferred that the data observed in the case of LD converter are located more closely to the equilibrium line than those in openhearth furnace.

From the survey of the experimental data ${ }^{3,4)}$ obtained by changing the feeding rate of oxygen in LD converter, it has been found that the deviation of the concentration relation between $\underline{\mathrm{C}}$ and $\underline{\mathrm{O}}$ from the equilibrium line is enlarged by the increase in the feeding rate of oxygen. This means that the increase in $\overrightarrow{\mathrm{LK}}$ caused by the increase in the feeding rate of oxygen becomes larger than the increase in $\overrightarrow{\mathrm{LN}}$.

In the case of crucible the driving force, $\overrightarrow{\mathrm{LK}}$, becomes very small, since a small amount of weak-oxidizing gas is used. On the other hand, the mixing of molten steel becomes violent, as the high frequency induction equipment is adopted for the promotion of mixing. Thereby, it may be estimated qualitatively that the points representing the concentration relation between $\underline{\mathrm{C}}$ and $\underline{\mathrm{O}}$ in crucible approach to or almost exist on the equilibrium line.

\section{Proceeding Sequence of Oxidation}

Applying the same idea for the concentration relations between $\underline{\mathrm{C}}$ and $\underline{\mathrm{O}}$ to those of $\underline{\mathrm{C}}-\underline{\mathrm{Si}}-\underline{\mathrm{O}}$ and $\underline{\mathrm{C}}-$ $\underline{\mathrm{Mn}}$ - systems, it can be explained qualitatively that in the case of LD converter the oxidations of silicon and manganese take place precedently in comparison with the decarburization and that the decarburization proceeds preferentially in the case of crucible.

In Fig. 2, the concentration relations of $\underline{\mathrm{C}}-\underline{\mathrm{Si}}-\underline{\mathrm{O}}$ and $\underline{\mathrm{C}}-\mathrm{Mn}-\underline{\mathrm{O}}$ systems are illustrated in the rectangular coordinates $(X-Y-Z)$. Where, coordinate axes of $X, Y$, and $Z$ represent the concentrations of $\underline{\mathrm{C}}, \underline{\mathrm{Si}}$, or $\underline{\mathrm{Mn}}$ and $\underline{\mathrm{O}}$, respectively. The equilibrium lines of $X$ to $Z$ and of $Y$ to $Z$ are illustrated by curve (1) on the plane of $X v s . Z$ and by curve (2) on the plane of $Y v s$. $Z$, respectively, and each equilibrium line forms the curved surface parallel to $Y$ - and $X$-axes, respectively. The intersection of these curved surface builds up the equilibrium line (curve (3)) in a three-dimensional system. If the system was in the equilibrium state, the concentration relation of each component of the system would be represented by this curve (3).

Now, Eq. (1) represents the operating line for the binary system. From the mass balance concerning oxygen, Eq. (3) can be obtained for the ternary system.

$$
\begin{aligned}
\int_{0}^{\Theta}(S / W) d \Theta= & \left(C_{\mathrm{O}}-C_{i, \mathrm{o}}\right)+\left(M_{\mathrm{O}} / M_{\mathrm{C}}\right)\left(C_{i, \mathrm{C}}-C_{\mathrm{C}}\right) \\
& +2\left(M_{\mathrm{O}} / M_{\mathrm{Si}}\right)\left(C_{i, \mathrm{Si}}-C_{\mathrm{Si}}\right) \ldots \ldots \ldots \ldots \ldots
\end{aligned}
$$




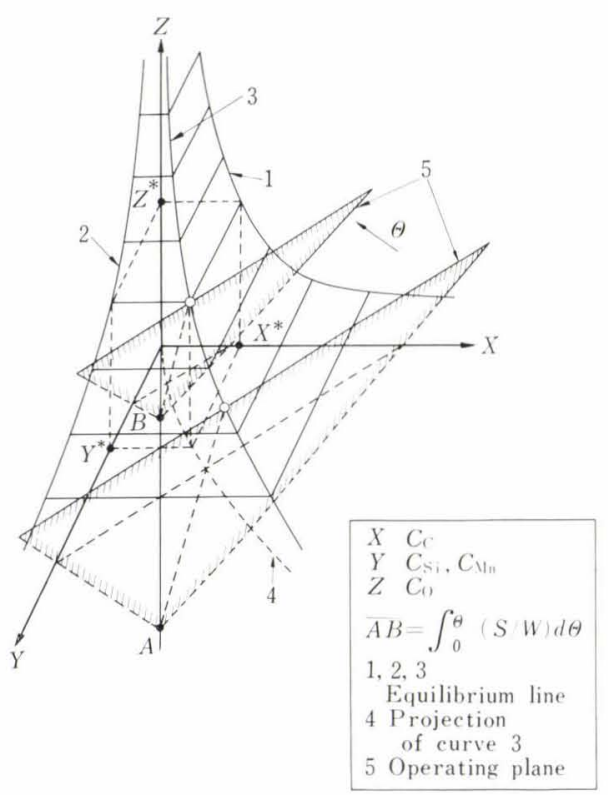

Fig. 2. Schematic diagram of the equilibrium line and the operating planes given in rectangular coordinates

As shown in Fig. 2, Eq. (3) represents the operating plane which moves to the direction of the arrow as the blowing time proceeds. In the same manner as the case of binary system, the two kinds of driving forces may be considered for the ternary system. Namely, one force has an essential tendency to move the system to the point of intersection of the operating plane and the equilibrium line and the other has a tendency to shift the system to the positive direction of $Z$-coordinate, and the transitional path of the system during the progress of blowing may be determined by the balance of these driving forces.

Usually, the experimental operations in crucible are conducted under a comparatively high temperature, and so the equilibrium relation between $Y$ and $Z$ ( $\underline{\mathrm{Si}}$ and $\underline{\mathrm{O}}$, or $\underline{\mathrm{Mn}}$ and $\underline{\mathrm{O}}$ ) may be given at a distant position from both $Z$ - and $Y$-coordinates. On the other hand, since the equilibrium relation between $Z$ and $X(\underline{\mathrm{O}}$ and $\underline{\mathrm{C}})$ is not affected very much by the temperature, the intersecting curve (equilibrium line (3)) of the curved surface formed by the equilibrium relation between $\underline{\mathrm{O}}$ and $\underline{\mathrm{Si}}$ or between $\underline{\mathrm{O}}$ and $\underline{\mathrm{Mn}}$ and the one formed by the equilibrium relation between $\underline{\mathrm{O}}$ and $\underline{\mathrm{C}}$ may be projected near $Y$-coordinate on $X-Y$ plane $(\underline{\mathrm{C}}-\underline{\mathrm{Si}}$ or $\underline{\mathrm{G}}-\mathrm{Mn})$. Hence, the point of intersection of the operating plane and the equilibrium line (3) in Fig. 2 exists near $Z-Y$ plane, and consequently the system may be drawn toward this point due to the driving force allowing the system to approach to the equilibrium. Thus the system may be attracted at first from the point shown by the initial concentrations of the system to the direction of $Y$-coordinate and then to the direction of the origin. Therefore, it may be considered in the case of the refining conducted in curcible that in an early stage of the process the decarburization proceeds preferentially in comparison with the oxidations of silicon and manganese.

In LD converter, since the temperature of molten steel at an early stage of blowing process is compara- tively low, the equilibrium line of $Z$ to $Y$ may be expressed near both $Z$ - and $Y$-coordinate axes, and it may be projected in the neighbourhood of $X$-coordinate axis on $X-Y$ plane. From this reason, at first the system may be attracted to the direction of $Y$-coordinate axis and then to the direction of the origin. That is, in the case of the blowing process in LD converter the oxidations of silicon and manganese take place earlier than the decarburization. Furthermore, since the temperature of molten steel in LD converter rises during the progress of blowing time, the equilibrium line projected on $X-Y$ plane moves from the side of $X$-axis to that of $Y$-axis. Since the more violent the mixing of molten steel in LD converter becomes, the more rapidly the system approaches to the equilibrium state, it may be considered in the case of violent mixing that the oxidation of silicon takes place more rapidly at an early blowing time than the decarburization. Actually, it was found in the experiments conducted by Watanabe, et al..$^{5)}$ that the oxidation of silicon took place more rapidly than the decarburization if the both has a deep cavity.

\section{Extension to Multicomponent System}

In the preceding paragraph the binary and ternary systems have been taken into consideration, and in this paragraph the previous analysis is extended to the multicomponent system. Corresponding to Eq. (1) for the binary system and Eq. (3) for the ternary system, Eq. (4) can be obtained from the mass balance on oxygen for the multicomponent system.

$$
\begin{array}{r}
\int_{0}^{\Theta}(S / W) d \Theta=\left(C_{1}-C_{i, 1}\right)+\sum_{j=2}^{n} \alpha_{j}\left(M_{\mathrm{O}} / M_{j}\right)\left(C_{i, j}-C_{j}\right), \\
(j=2, \ldots, n) \ldots \ldots(4)
\end{array}
$$

where, $j=1,2, \ldots, n$ represents such component as $\underline{\mathrm{O}}$, $\underline{\mathrm{C}}, \underline{\mathrm{Si}}, \underline{\mathrm{Mn}}, \mathrm{P}, \ldots$, respectively, and $\alpha_{j}$ is the stoichiometric coefficient representing the number of atoms of oxygen, $\underline{\mathrm{O}}$, which reacts with an atom of $j$-component.

The concentration of $j$-component in equilibrium state, $C_{j}^{*}$, can be described as functions of the oxygen concentration, $C_{1}^{*}$, and of the temperature of molten steel by the use of the equilibrium concentration relation, as follows:

$$
C_{j}^{*}=F_{j}\left(C_{1}^{*}, T\right), \quad(j=2, \ldots, n) .
$$

Polynomial regarding to $C_{1}^{*}$ can be obtained by substituting Eq. (5) into Eq. (4) described for the equilibrium state. By giving the initial concentrations of each component, $C_{i, j}$, the equilibrium concentration of oxygen, $C_{1}^{*}$ can be determined from the polynomial mentioned above. And so, the equilibrium concentration of each component, $C_{j}^{*}(j=2, \ldots, n)$, can be obtained by substituting $C_{1}^{*}$ into Eq. (5).

Considering that the rate of the concentration change of each component may be determined from the balance of driving forces, Eq. (6) regarding to oxygen and Eq. (7) relevant to the other $j$-components can be described, as follows:

$$
\begin{aligned}
& d C_{1} / d \Theta=I\left(C_{1}^{*}-C_{1}\right)+S / W \ldots \ldots \ldots \ldots \ldots \\
& d C_{j} / d \Theta=I\left(C_{j}^{*}-C_{j}\right), \quad(j=2, \ldots, n) \ldots \ldots
\end{aligned}
$$

where, the mass transport factor, $I$, is defined by Eqs. 
(6) and (7), and I may be considered as the factor indicating the degree of mixing of molten steel.

Oxidations of molten steel in the refining process are consisted of each elementary-reaction process and of the mass transfer steps, but since the refining process proceeds usually at high temperature, each elementary-reaction process may be considered as a rapid one. Hence, the mass transfer in the refining process is assumed to be the rate-controlling step.

Now, it may be assumed that there exist $m$-steps of the elementary-mass transfer during the progress of the process where $j$-component approaches to the equilibrium state. Here, the rate of mass transfer, the concentration and the resistance for the transfer of $j$ component in the $k$-th step on the way to the equilibrium are signified by $n_{j, k}, C_{j, k}$ and $R_{j, k}$, respectively. If $n_{j, k}$ is described by Eq. (8), then under the assumption of the quasi steady-state conditions for each step, the overall rate of mass transfer, $\mathcal{N}_{j}$, can be presented by Eq. (9).

$$
\begin{aligned}
n_{j, k}= & \left(1 / R_{j, k}\right)\left(C_{j, k}-C_{j, k-1}\right), \\
& (k=1, \ldots, m, j=2, \ldots, n) \ldots .(8) \\
\mathcal{N}_{j}= & W \cdot d C_{j} / d \Theta=U_{j}\left(C_{j, m}-C_{j, 0}\right) \\
= & U_{j}\left(C_{j}^{*}-C_{j}\right), \quad(j=2, \ldots, n) \ldots \ldots(9)
\end{aligned}
$$

where, $U_{j}$ is a function of $R_{j, k}(k=1, \ldots, m)$, and it becomes equal to $\left(\sum_{k=1}^{m} R_{j, k}\right)^{-1}$ when the all resistances are assumed to be in series. Furthermore, $C_{j, 0}$, in Eq. (9) means the concentration of $j$-component supplied from the bulk of molten steel to the first step, and $C_{j, m}$ means the concentration of the $j$-component discharged from the $m$-th step where the system is assumed to be in the equilibrium state. Hence, $C_{j, 0}$ and $C_{j, m}$ can be replaced by $C_{j}$ and $C_{j}^{*}$ respectively. Since the elementary-reaction processes and the mass transfer steps are included in the refining process, a coefficient, $U_{j}$, defined by Eq. (9) may be considered as the rate constant of overall reaction where the rate of reaction is faster than the rates of mass transfer.

Now, dividing both sides of Eq. (9) by the mass of molten steel, $W$, Eq. (10) is obtained.

$$
d C_{j} / d \Theta=\left(U_{j} / W\right)\left(C_{j}^{*}-C_{j}\right) .
$$

From the comparison of Eq. (10) with Eq. (7), the relation between $U_{j}$ and $I$ may be expressed as $U_{j}=$ $I \cdot W$. Consequently, it may be considered that the value of $I$ depends on the kind of components, but as described later, the results calculated by using the same value of $I$ in regard to the transitional variations of the concentration of each component are in good agreement with the experimental data. From this fact, it is guessed that $U_{j}$ may not be affected very much by the kind of components.

For the equilibrium state, Eq. (4) can be rewritten by Eq. (11).

$$
\int_{0}^{\Theta}(S / W) d \Theta=\left(C_{1}^{*}-C_{i, 1}\right)+\sum_{j=2}^{n} \alpha_{j}\left(M_{\mathrm{O}} / M_{j}\right)\left(C_{i, j}-C_{j}^{*}\right)
$$

Eq. (12) is obtained from Eqs. (4) and (11),

$$
\left(C_{1}-C_{1}^{*}\right)-\sum_{j=2}^{n} \alpha_{j}\left(M_{\mathrm{o}} / M_{j}\right)\left(C_{j}-C_{j}^{*}\right)=0
$$

differentiating Eq. (4) with respect to $\Theta$.

$$
S / W=d C_{1} / d \Theta+\sum_{j=2}^{n} \alpha_{j}\left(M_{\mathrm{o}} / M_{j}\right)\left(-d C_{j} / d \Theta\right) .
$$

Substituting Eq. (10) into Eq. (13), and applying the relation of $U_{j}=I \cdot W$, Eq. (14) is obtained.

$$
S / W=d C_{1} / d \Theta+I \cdot \sum_{j=2}^{n} \alpha_{j}\left(M_{\mathrm{O}} / M_{j}\right)\left(C_{j}-C_{j}^{*}\right)
$$

Also, Eq. (6) can be derived by substituting Eq. (12) into Eq. (14). Namely, it may be found that Eqs. (6) and (7) expressed on the basis of the concept of the balance between the driving forces can also be derived from Eq. (4) representing the mass balance for oxygen and Eq. (9) relevant to the rate of mass transfer.

In the analysis of the vacuum degassing process, Nemoto et al. ${ }^{6}$ ) reported that the operating time was linearly related to the difference between the carbon concentration in a ladle and the equilibrium concentration on a semilogarithmic graph paper. This means that the coefficient, I, in Eq. (7) is constant actually.

Now, Eqs. (4) to (7) are rewritten by Eqs. (15) to (18), respectively.

$$
\begin{array}{rlrl}
\int_{0}^{\theta} B d \theta & =\left(c_{1}-c_{i, 1}\right)+\sum_{j=2}^{n} \alpha_{j}\left(M_{\mathrm{o}} / M_{j}\right)\left(c_{i, j}-c_{j}\right) \ldots \ldots \\
c_{j}^{*} & =f_{j}\left(c_{1}^{*}, t\right), & (j=2, \ldots, n) \ldots \ldots \\
d c_{1} / d \theta & =A\left(c_{1}^{*}-c_{1}\right)+B & \ldots \ldots \ldots \ldots \ldots \ldots \ldots \ldots \ldots \\
d c_{j} / d \theta & =A\left(c_{j}^{*}-c_{j}\right), & (j=2, \ldots, n) \ldots \ldots
\end{array}
$$

where, $A \equiv I \Theta_{t}, \quad B \equiv S \Theta_{t} / W C_{i, \mathrm{c}}, \quad c_{j} \equiv C_{j} / C_{i, \mathrm{c}}, \quad t \equiv T / T_{i}$, $\theta=\Theta \mid \Theta_{t}$ and $f_{j}$ in Eq. (16) corresponds to $F_{j}$ in Eq. (5).

The value of $c_{1}^{*}$ can be obtained by solving Eq. (15) for the equilibrium state and Eq. (16) simultaneously. The values of $c_{j}^{*}(j=2, \ldots, n)$ can be obtained by substituting the value of $c_{1}^{*}$ into Eq. (16). The transitional variations of the concentrations of each component in molten steel during the progress of blowing time can be calculated by substituting the values of $c_{1}^{*}$ and $c_{j}^{*}(j=2, \ldots, n)$ into Eqs. (16) and (17), respectively.

\section{Consideration on the Factors of $A$ and $B$}

Dimensionless factor, $A$, is defined by the relation of $A \equiv I \Theta_{t}=U_{j} \Theta_{t} / W$, and it means the mass of molten steel transported per a unit mass of molten steel. When $A$ shows a large value at a given refining time, it means that the mixing of molten steel is violent. The differences between the concentrations of each component in molten steel and those in equilibrium state can be determined by the value of $A$. From Eqs. (17) and (18), $c_{j}$ becomes equal to $c_{*}^{*}(j=1, \ldots, n)$ at $A=\infty$, and the relations of

$$
c_{1}=\int_{0}^{\theta} B d \theta+c_{i, 1} \text { and } c_{j}=c_{i, j}(j=2, \ldots, n)
$$

can be obtained for $A=0$.

For a very large value of $A$, it can be seen from the result mentioned above that the concentrations of each component in molten steel, $c_{j}(j=1, \ldots, n)$, approach to the equilibrium concentrations, $c_{j}^{*}(j=1, \ldots, n)$, 
which changes during the progress of blowing time. As the concentrations, $c_{1}^{*}$, represents the lowest concentration of oxygen, the oxygen concentration becomes very low in such a case mentioned above.

On the other hand, the value of $A$ becomes small when the mixing of molten steel is mild. Since the progress of oxidation is retarded when the value of $A$ is very low, the concentrations of each component except oxygen become nearly equal to the values of the initial concentrations, $c_{i, j}$, and the oxygen concentration shows a very high value.

Furthermore, the factor, $B$, is defined by the relation of $B \equiv S \Theta_{t} / W C_{i, \mathrm{C}}$, and it means the ratio of the effective mass of oxygen supplied into molten steel to the initial mass of carbon in molten steel.

It is well known that the quality of steel depends largely on the level of oxygen concentration in molten steel, and the level in the various refining processes can be determined by the two characteristic factors, $A$ and $B$, defined in this work. For instance, the level in a degassing process may be determined by only $A$, since the desorption and the absorption of oxygen do not take place in the process. The increases in the value of $B$ and also in the oxygen concentration in molten steel are caused by the increase in the flow rate of oxygen during a given blowing time, but $A$ acts to diminish the increase in the oxygen concentration.

Now, the value of $B$ can be obtained from the operating conditions, but the value of $A$ can not be evaluated unless the rate constant of the overall reaction, $U_{j}$, is represented as a function of the operating conditions. The information concerning the possibility that the oxygen concentration can be reduced to what extent by the increase in the value of $A$ may be obtained by evaluating such the value of $A$ that the results calculated from the foregoing model coincide closely with the observed data relevant to the transitional variations of the concentrations, and the increase in the value of $A$ may be realized by increasing the degree of mixing.

Various components have been taken into account in this work, but the change in the values of $U_{j}$ due to the kind of components has not been found as described later. Hence, in the case of refining process under the similar operating conditions, it may be allowed to take the same value of $A$ regardless of the kind of components, and consequently, the transitional variations in the concentrations of each component in molten steel may be evaluated by adopting a single value for $A$ and also for $B$.

\section{Analysis of the Data Obtained by the Refin- ing Experiments in Crucibles}

\section{Fe-Si System}

Refining experiments made on the Fe-Si system by using gaseous mixtures of $\mathrm{Ar}, \mathrm{H}_{2}$, and $\mathrm{H}_{2} \mathrm{O}$ in $\mathrm{MgO}$ crucibles were conducted by Kawai et al. ${ }^{7)}$ under the constant partial pressure of steam and the constant temperature of molten steel. For these experiments, Eqs. (15) and (16) can be rewritten as Eqs. (19) and (20).

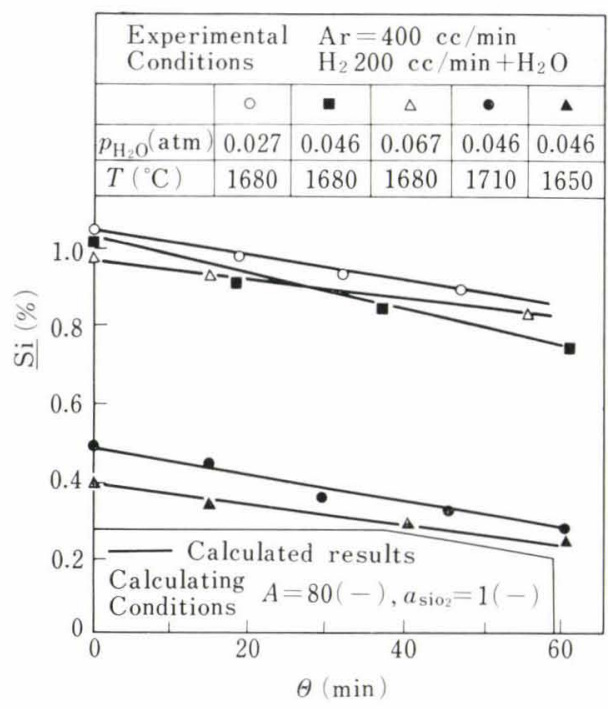

Fig. 3. Comparison of the calculated results with the data observed by Kawai et al. ${ }^{7)}$ in regard to the concentration of silicon in $\mathrm{Fe}-\mathrm{Si}$ alloys

$$
\begin{aligned}
\int_{0}^{\theta} B d \theta= & \left(c_{0}-c_{i, \mathrm{O}}\right)+2\left(M_{\mathrm{O}} / M_{\mathrm{Si}}\right)\left(c_{i, \mathrm{Si}}-c_{\mathrm{Si}}\right) \ldots \ldots . \\
c_{\mathrm{O}}^{2} \cdot c_{\mathrm{Si}}= & a_{\mathrm{SiO}_{2}} \cdot \exp \{2.303(-30720 / \mathrm{T} \\
& +11.76)\} /\left(C_{i, \mathrm{C}} \times 10^{2}\right)^{3} \quad \ldots \ldots \ldots \ldots \ldots(2)
\end{aligned}
$$

The value of $a_{\mathrm{SiO}_{2}}$ has been assumed to be 1 , since it was inferred by them ${ }^{7}$ from the analytical results of the slag samples attached to a quartz tube that the slag of $\mathrm{FeO}-\mathrm{SiO}_{2}$ system was saturated with $\mathrm{SiO}_{2}$. For the calculations of the concentrations of silicon and oxygen, the temperature of molten steel and the initial concentration of silicon in molten steel have been taken as equal to the data adopted in their experiments, and the flow rate of oxygen used in the calculations have been estimated from the numerical analysis of the experimental data. The initial concentration of oxygen has been estimated from the assumption that the system was in the equilibrium state at the beginning of the measurement. The value of $A$ has been assumed to be equal to 80 , and also the same value has been used in the calculations relevant to the other systems in crucible as described later.

In Fig. 3 the calculated results concerning the transitional variations of the concentration of silicon for the Fe-Si system have been compared with the experimental data reported by them, ${ }^{7}$ and there are close agreements between the observed data and the calculated results regardless of the experimental conditions such as temperature, concentration and partial pressures of steam.

\section{Fe-C-Si System}

Refining experiments of the $\mathrm{Fe}-\mathrm{C}-\mathrm{Si}$ system by gaseous mixtures of $\mathrm{Ar}$ and steam in $\mathrm{MgO}$ crucibles were conducted by Kawai et al. ${ }^{7}{ }^{\text {) }}$ under the various experimental conditions. Similar experiments conducted by gaseous mixtures of $\mathrm{Ar}$ and $\mathrm{CO}_{2}$ in $\mathrm{MgO}$ crucibles were made by Niiri et al. ${ }^{9}{ }^{\text {) }}$

For these cases, Eq. (15) can be rewritten as Eq. (21), and Eq. (16) may be given by Eqs. (22) and (20). 


$$
\begin{aligned}
\int_{0}^{\theta} B d \theta= & \left(c_{\mathrm{O}}-c_{i, 0}\right)+\left(M_{\mathrm{O}} / M_{\mathrm{C}}\right)\left(c_{i, \mathrm{C}}-c_{\mathrm{C}}\right) \\
& +2\left(M_{\mathrm{O}} / M_{\mathrm{Si}}\right)\left(c_{i, \mathrm{Si}}-c_{\mathrm{Si}}\right) \ldots \ldots \ldots . . \\
c_{\mathrm{O}} \cdot c_{\mathrm{C}}= & p_{\mathrm{CO}} \cdot \exp \{2.303(-1160 / T \\
& -2.003)\} /\left(C_{i, \mathrm{C}} \times 10^{2}\right)^{2} \ldots \ldots \ldots
\end{aligned}
$$

The value of $a_{\mathrm{SiO}_{2}}$ has been assumed to be 1 as in the case of $\mathrm{Fe}-\mathrm{Si}$ system. Furthermore, $p_{\mathrm{CO}}=0.1 \mathrm{~atm}$ has been adopted for the experiments conducted by Kawai et al. ${ }^{7}$ ) whereat the rate of decarburization was comparatively slow, and $p_{\mathrm{Co}}=0.5 \mathrm{~atm}$ for the experiments made by Niiri et al. ${ }^{9)}$ whereat the rate of decarburization was comparatively fast. By considering the rates of decarburization, in regard to the partial pressure of $\mathrm{CO}, p_{C O}=0.5 \mathrm{~atm}$ or $0.1 \mathrm{~atm}$ have been chosen for the other systems as described later.

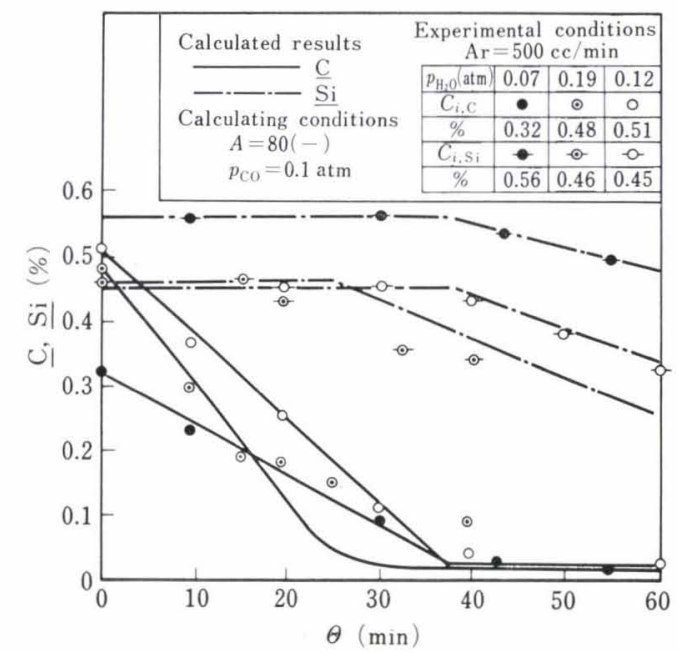

Fig. 4. Comparison of the calculated results with the data observed by Kawai et al. ${ }^{7}$ in regard to the concentrations of carbon and of silicon in $\mathrm{Fe}-\mathrm{C}-\mathrm{Si}$ alloys at $1650^{\circ} \mathrm{C}$

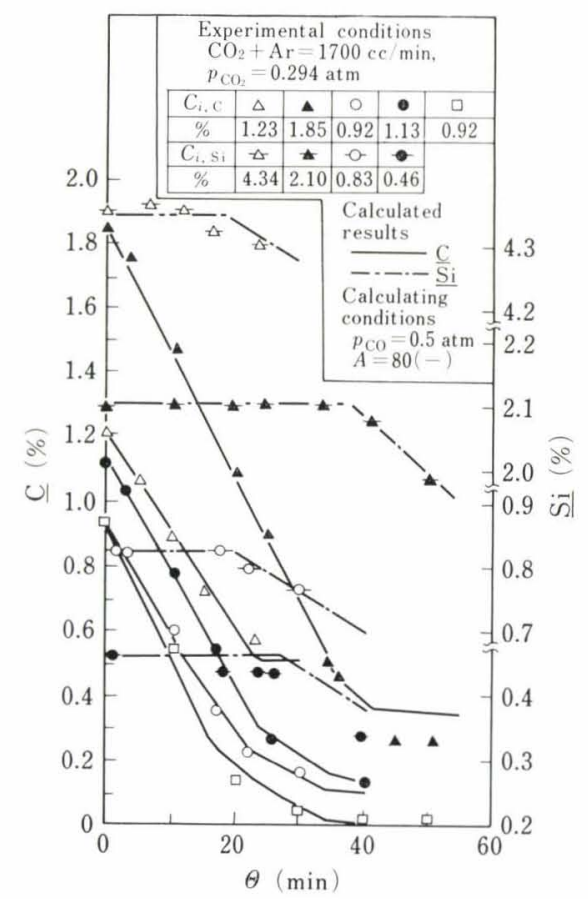

Fig. 5. Comparison of the calculated results with the data observed by Niiri et al. ${ }^{9)}$ in regard to the concentrations of carbon and of silicon in $\mathrm{Fe}-\mathrm{C}-\mathrm{Si}$ alloys at $1600^{\circ} \mathrm{C}$
Comparisons of the calculated results with the experimental data relevant to the concentrations of carbon and silicon in the $\mathrm{Fe}-\mathrm{C}-\mathrm{Si}$ system are illustrated in Figs. 4 and 5, and the close agreements between them have been obtained in spite of the differences in the experimental conditions adopted by these investigators such as the temperatures and the initial concentrations of molten steel.

\section{3. $\mathrm{Fe}-\mathrm{C}-\mathrm{Cr}$ System}

Refining experiments for the $\mathrm{Fe}-\mathrm{C}-\mathrm{Cr}$ system by gaseous mixtures of $\mathrm{Ar}$ and $\mathrm{CO}_{2}$ in $\mathrm{MgO}$ crucibles were conducted by Niiri et al. ${ }^{9)}$ under the various experimental conditions. For these experiments, Eq. (15) can be expressed by Eq. (23) and Eq. (16) can be given by Eqs. (24) and (22).

$$
\begin{aligned}
\int_{0}^{\theta} B d \theta= & \left(c_{\mathrm{O}}-c_{i, \mathrm{O}}\right)+\left(M_{\mathrm{O}} / M_{\mathrm{C}}\right)\left(c_{i, \mathrm{C}}-c_{\mathrm{C}}\right) \\
& +2\left(M_{\mathrm{O}} / M_{\mathrm{Cr}}\right)\left(c_{i, \mathrm{Cr}}-c_{\mathrm{Cr}}\right) \ldots \ldots \ldots \ldots \\
c_{\mathrm{O}}^{2} \cdot c_{\mathrm{Cr}}= & {\left[a_{\mathrm{FeCr}_{2} \mathrm{O}_{4}} \cdot \exp \{2.303(-54300 / T\right.} \\
& +23.44)\}]^{1 / 2} /\left(C_{i, \mathrm{C}} \times 10^{2}\right)^{3} \ldots \ldots \ldots \ldots
\end{aligned}
$$

The activity of $\mathrm{FeCr}_{2} \mathrm{O}_{4}$ has been assumed to be 1. Numerical calculations have been made by using the same values as adopted in the experimental conditions. In regard to the concentrations of carbon and chromium in the $\mathrm{Fe}-\mathrm{C}-\mathrm{Cr}$ system, the comparison of the calculated results with the experimental data has been illustrated in Fig. 6. The transitional variations in the concentrations of carbon and chromium are agreed very well with each other.

\section{Fe-Si-Mn System}

By using gaseous mixtures of Ar-steam and of $\mathrm{Ar}-\mathrm{O}_{2}$, Kawai et al. ${ }^{7}$ ) made the refining experiments of the $\mathrm{Fe}-\mathrm{Si}-\mathrm{Mn}$ system in $\mathrm{MgO}$ crucible under various ex-

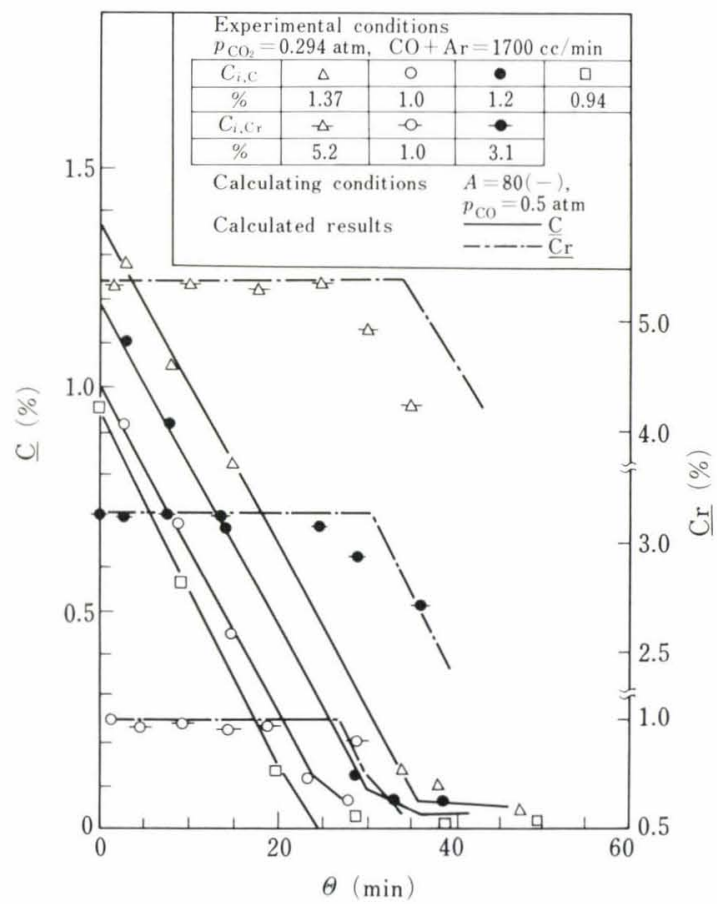

Fig. 6. Comparison of the calculated results with the data observed by Niiri et al. ${ }^{9)}$ in regard to the concentrations of carbon and of chromium in $\mathrm{Fe}-\mathrm{C}-\mathrm{Cr}$ alloys at $1600^{\circ} \mathrm{C}$ 


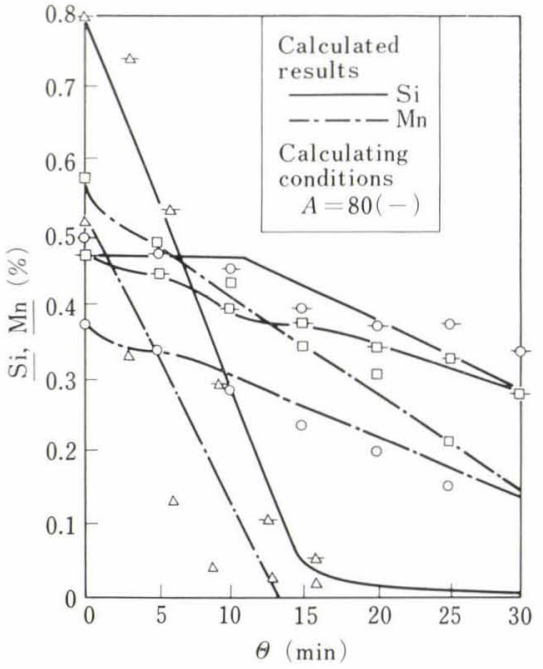

Experimental conditions

\begin{tabular}{cccccccr}
$C_{i, \mathrm{Si}}$ & $(\%)$ & $C_{i, \mathrm{Mn}}$ & $(\%)$ & ${ }^{\circ} \mathrm{C}$ & $\begin{array}{c}p_{\mathrm{H}_{2} \mathrm{O}} \\
(\mathrm{atm})\end{array}$ & $\begin{array}{c}\mathrm{O}_{2} \\
(\mathrm{cc} / \mathrm{min})\end{array}$ & $\begin{array}{c}\mathrm{Ar} \\
(\mathrm{cc} / \mathrm{min})\end{array}$ \\
\hline$\triangle$ & 0.79 & $-\triangle-$ & 0.52 & 1600 & 0 & 200 & 1300 \\
$\bigcirc$ & 0.48 & $-\mathrm{O}^{-}$ & 0.37 & 1650 & 0.07 & 0 & 500 \\
$\square$ & 0.47 & $-\square-$ & 0.56 & 1650 & 0.12 & 0 & 500
\end{tabular}

Fig. 7. Comparison of the calculated results with the data observed by Kawai et al. ${ }^{71}$ in regard to the concentrations of silicon and of manganese in $\mathrm{Fe}-\mathrm{Si}-\mathrm{Mn}$ alloys at $1600^{\circ}$ and $1650^{\circ} \mathrm{C}$

perimental conditions. For these experiments, Eq. (15) can be expressed by Eqs. (25) and (16) may be given by Eqs. (20) and (26).

$$
\begin{aligned}
& \int_{0}^{\theta} B d \theta=\left(c_{\mathrm{O}}-c_{i, \mathrm{O}}\right)+2\left(M_{\mathrm{o}} / M_{\mathrm{Si}}\right)\left(c_{i, \mathrm{Si}}-c_{\mathrm{Si}}\right) \\
& +\left(M_{\mathrm{O}} / M_{\mathrm{Mn}}\right)\left(c_{i, \mathrm{Mn}}-c_{\mathrm{Mn}}\right) \\
& c_{\mathrm{O}} \cdot c_{\mathrm{Mn}}=a_{\mathrm{MnO}} \cdot \exp \{2.303(-15050 / \mathrm{T} \\
& +6.81)\} /\left(C_{i, \mathrm{c}} \times 10^{2}\right)^{2}
\end{aligned}
$$

The values of $a_{\mathrm{SiO}_{2}}$ and $a_{\mathrm{MnO}}$ have been expressed as a function of the concentrations of manganese and silicon in molten steel on the basis of the figure given by Richardson et al. ${ }^{10)}$ A comparison between the calculated and the observed results is illustrated in Fig. 7.

\section{Extended Application to Reaction-controlling Process}

\section{Degassing Process in Fe-C-O System}

By the use of levitation technique in which a drop of molten iron containing oxygen and carbon was floated in a gas stream of argon, Sakao et al. ${ }^{11)}$ investigated the degassing process according to the reaction expressed by Eq. (27), and reported that the product of the oxygen concentration by the carbon concentration in the drop was in proportion to the degassing rate.

$$
\underline{\mathrm{C}}+\underline{\mathrm{O}}=\mathrm{CO} .
$$

Furthermore, they ${ }^{11)}$ reported that the experimental results relevant to the transitional variations in the concentrations of carbon and oxygen in the iron drop could be expressed by straight lines with the same

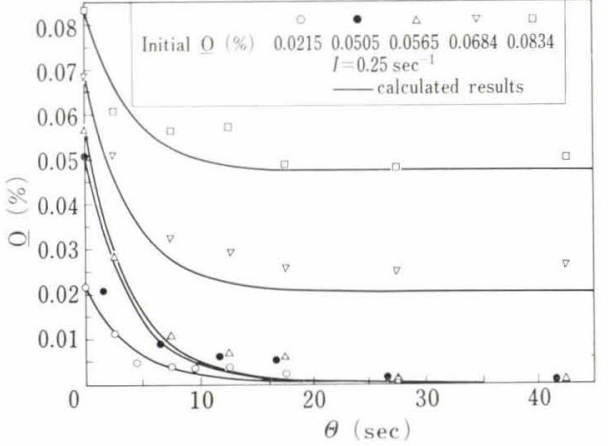

Fig. 8. Comparison of the calculated results with the data observed by Sakaoet al. ${ }^{11)}$ in regard to the concentration of oxygen in the drop of iron melt at $1800^{\circ} \mathrm{C}$

slope as that of operating lines shown in Fig. 1.

In this case, as oxygen is not supplied to the drop during the process, Eq. (4) can be expressed by Eq. (28), and as there is no $\mathrm{CO}$ gas in the fresh gas stream contacting with the drop, Eq. (5) can be rewritten as Eq. (29),

$$
\begin{aligned}
& \left(C_{\mathrm{O}}-C_{i, \mathrm{o}}\right)+\left(M_{\mathrm{O}} / M_{\mathrm{C}}\right)\left(C_{i, \mathrm{C}}-C_{\mathrm{C}}\right)=0 . \\
& C_{\mathrm{C}}^{*} \cdot C_{\mathrm{O}}^{*}=0 \quad \ldots \ldots \ldots \ldots \ldots \ldots \ldots \ldots \ldots \ldots \ldots \ldots \ldots \ldots \ldots \ldots \ldots \ldots
\end{aligned}
$$

Moreover, Eqs. (6) and (7) are expressed by Eqs. (30) and (31), respectively.

$$
\begin{aligned}
& d C_{\mathrm{O}} / d \theta=I\left(C_{\mathrm{O}}^{*}-C_{\mathrm{O}}\right) \\
& d C_{\mathrm{C}} / d \theta=I\left(C_{\mathrm{C}}^{*}-C_{\mathrm{C}}\right)
\end{aligned}
$$

As seen from Eq. (29), each case where $C_{0}^{*}$ or $C_{\mathrm{C}}^{*}$ equals to zero may be supposed. For the case of $C_{\mathrm{c}}^{*}=0$, solving Eq. (30) with respect to the oxygen concentration under the condition of $C_{0}=C_{i, 0}$ at $\Theta=$ 0, Eq. (32) is obtained. Furthermore, solving Eq. (31) with respect to the carbon concentration, and combining Eq. (28) written in the equilibrium state with the solution of Eq. (31), Eq. (33) is obtained.

$$
\begin{aligned}
& C_{\mathrm{O}}=C_{i, \mathrm{O}} \cdot \exp (-I \Theta) \ldots \ldots \ldots \ldots \ldots \ldots \ldots \ldots \ldots \ldots \ldots \ldots \\
& C_{\mathrm{C}}=C_{i, \mathrm{C}}-\left(M_{\mathrm{C}} / M_{\mathrm{O}}\right) C_{i, \mathrm{O}}\{1-\exp (-I \Theta)\} \ldots
\end{aligned}
$$

Eqs. (32) and (33) can be applied to the determination of the transitional variations of the oxygen and carbon concentrations in the case of $C_{i, \mathrm{c}} / C_{i, \mathrm{O}} \geq$ (12/16).

With the same procedure, Eqs. (34) and (35) are obtained for the case of $C_{0}^{*}=0$.

$$
\begin{aligned}
& C_{0}=C_{i, \mathrm{O}}-\left(M_{\mathrm{O}} / M_{\mathrm{C}}\right) C_{i, \mathrm{C}}\{1-\exp (-I \Theta)\} \ldots \\
& C_{\mathrm{C}}=C_{i, \mathrm{C}} \cdot \exp (-I \Theta)
\end{aligned}
$$

Similarly, Eqs. (34) and (35) can be applied to the case of $C_{i, \mathrm{c}} / C_{i, \mathrm{O}} \leq(12 / 16)$.

The results calculated from Eqs. (30) to (33) are shown in Figs. 8 and 9 as compared with the empirical data. ${ }^{11)}$ In Fig. 8, the observed data of the oxygen concentration deviate to some extent from the theoretical curves, but the close coincidence of both results obtained in regard to the carbon concentration is seen in Fig. 9. In these numerical calculations, the value of $I$ has been assumed to be $0.25 \mathrm{sec}^{-1}$, and it is very large in comparison with the values of $I$ adopted in the cases described later. It may be considered that such a large value has resulted from the characteristics of the process of levitation. 


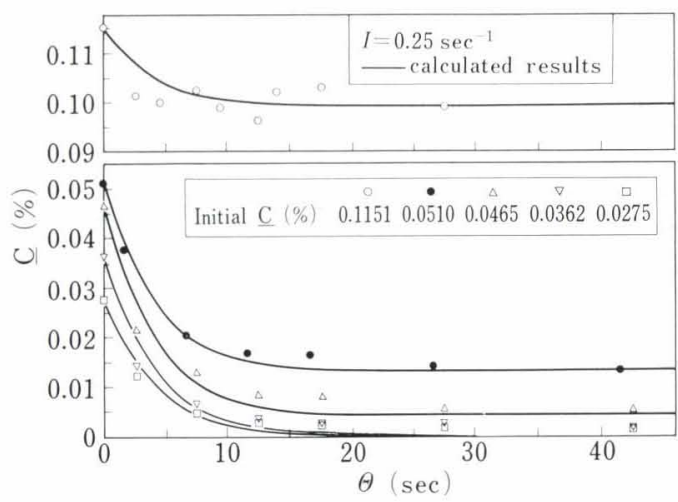

Fig. 9. Comparison of the calculated results with the data observed by Sakao et al. ${ }^{11}$ in regard to the concentration of carbon in the drop of iron melt at $1800^{\circ} \mathrm{C}$

\section{Simultaneous Reaction between Iron Melt and Mixture of $\mathrm{CO}$ and $\mathrm{CO}_{2}$}

Experiments blowing the gaseous mixture of $\mathrm{CO}$ and $\mathrm{CO}_{2}$ to the surface of molten iron in crucible were conducted by Mori et al., ${ }^{12}$ and the transitional variations of the concentrations of carbon and oxygen were investigated. They found that the oxygen concentration increases at first and then decreases in the case of low partial pressure of $\mathrm{CO}_{2}$, and that the carbon concentration shows the same trend in the case of high partial pressure of $\mathrm{CO}_{2}(c f$., Fig. 11). Such behaviors of the concentration of carbon and oxygen in iron melt as mentioned above were explained by the kinetic analysis $^{12}$ relevant to the simultaneous reactions given by Eqs. (36) to (38).

$$
\begin{aligned}
\mathrm{CO}_{2} & \rightleftharpoons \mathrm{CO}+\underline{\mathrm{O}} \\
2 \mathrm{CO} & \rightleftharpoons \mathrm{CO}_{2}+\underline{\mathrm{C}} \\
\underline{\mathrm{C}}+\underline{\mathrm{O}} & \rightleftharpoons \mathrm{CO} \ldots . . .
\end{aligned}
$$

Now, the application of the foregoing model to the $\mathrm{Fe}-\mathrm{C}-\mathrm{O}$ system is tried. Since not only oxygen but also carbon are supplied in this case, Eqs. (6) and (7) can be expressed by Eqs. (39) and (40), respectively.

$$
\begin{aligned}
& d C_{\mathrm{O}} / d \Theta=I\left(C_{\mathrm{O}}^{*}-C_{\mathrm{O}}\right)+S_{\mathrm{O}}(\Theta) / W \ldots . \\
& d C_{\mathrm{C}} / d \Theta=I\left(C_{\mathrm{C}}^{*}-C_{\mathrm{C}}\right)+S_{\mathrm{C}}(\Theta) / W \ldots
\end{aligned}
$$

Eq. (4) can be represented by Eq. (41).

$$
\int_{0}^{\Theta} \frac{S(\Theta)}{W} d \Theta=\left(C_{\mathrm{O}}-C_{i, \mathrm{O}}\right)+\left(\frac{M_{\mathrm{O}}}{M_{\mathrm{C}}}\right)\left(C_{i, \mathrm{C}}-C_{\mathrm{C}}\right) \ldots
$$

where, $S(\Theta)$ is a function of the elapsed time, $\Theta$, which is described by Eq. (42).

$$
S(\Theta)=S_{0}(\Theta)-\left(M_{\mathrm{O}} / M_{\mathrm{C}}\right) S_{\mathrm{C}}(\Theta)
$$

The equilibrium concentration of carbon, $C_{\mathrm{c}}^{*}$, can be expressed by Eq. (43) on the basis of the reaction of Eq. (38).

$$
C_{\mathrm{C}}^{*}=p_{\mathrm{Co}} / K(T) \cdot C_{0}^{*}
$$

Combining Eq. (41) written for the equilibrium state with Eq. (43) which is equivalent to Eq. (5), Eq. (44) representing the equilibrium concentration of oxygen, $C_{0}^{*}$, is derived.

$$
C_{0}^{*}=\left(-a+\sqrt{a^{2}-4 b}\right) / 2
$$

where, $a \equiv\left(M_{\mathrm{O}} / M_{\mathrm{C}}\right) C_{i, \mathrm{C}}-C_{i, \mathrm{O}}-\int_{0}^{\Theta}\{S(\Theta) / W\} d \Theta$,

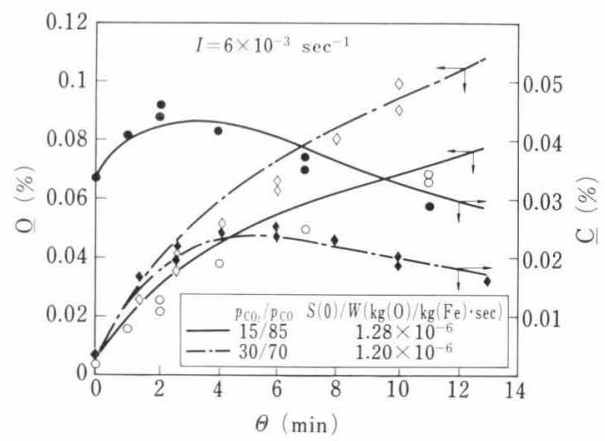

Fig. 10. Comparison of the calculated results with the data observed by Mori et al. ${ }^{21}$ ) in regard to the concentrations of oxygen and of carbon in iron melt at $1580^{\circ} \mathrm{C}$

$b \equiv-\left(M_{\mathrm{O}} / M_{\mathrm{C}}\right) p_{\mathrm{CO}} / K(T)$. Thus the values of $C_{\mathrm{o}}^{*}$ and $C_{\mathrm{C}}^{*}$ in Eqs. (39) and (40) may be determined by the use of Eqs. (43) and (44).

Now, in order to determine the values of $S_{0}(\Theta)$ and $S_{\mathrm{C}}(\Theta)$ in Eq. (42), the concentrations of oxygen and carbon in the case whereat the reaction system described by Eqs. (36) to (38) has reached ultimately its equilibrium state, $C_{0}^{e}$ and $C_{\mathrm{C}}^{e}$, are taken into account. These final-equilibrium concentrations of the simultaneous reaction can be determined by the values of $p_{\mathrm{CO}}, p_{\mathrm{CO} 2}$ and the temperature of molten steel which are given from the experimental conditions.

Namely, on the basis of Eqs. (36) and (37), $C_{0}^{e}$ and $C_{\mathrm{0}}^{e}$ are expressed by Eqs. (45) and (46), respectively.

$$
\begin{aligned}
& C_{\mathrm{O}}^{e}=K^{\prime}\left(p_{\mathrm{CO}_{2}} / p_{\mathrm{CO}}\right) . \\
& C_{\mathrm{C}}^{e}=K^{\prime \prime}\left(p_{\mathrm{CO}}^{2} / p_{\mathrm{CO}_{2}}\right) .
\end{aligned}
$$

where, $K^{\prime}$ and $K^{\prime \prime}$ are the equilibrium constants of the reactions described by Eqs. (36) and (37), respectively, and these values can be evaluated from the temperature of molten steel.

Assuming that $S_{0}(\Theta)$ and $S_{\mathrm{C}}(\Theta)$ are in proportion to the difference between the final-equilibrium concentration and the concentration at a voluntary time $\Theta$, Eqs. (47) and (48) may be obtained.

$$
\begin{aligned}
& S_{\mathrm{O}}(\Theta) / W=\beta\left(C_{\mathrm{O}}^{e}-C_{\mathrm{O}}\right) \\
& S_{\mathrm{C}}(\Theta) / W=\beta\left(C_{\mathrm{C}}^{e}-C_{\mathrm{C}}\right)
\end{aligned}
$$

where, $\beta$ is a proportional coefficient.

In Eq. (47), under a given value of $\beta, S_{\mathrm{O}}(\Theta)$ changes with the transitional variation in the value of $C_{0}$. Similarly, it may be seen from Eq. (48) that $S_{\mathrm{C}}(\Theta)$ varies with $C_{\mathrm{C}}$ during the blowing time. Giving the value of $\beta$ and the initial concentrations of oxygen and carbon, the initial values of $S_{0}$ and $S_{\mathrm{C}}$ (i.e., $S_{\mathrm{O}}(0)$ and $\left.S_{\mathrm{C}}(0)\right)$ may be calculated from Eqs. (47) and (48), respectively, and consequently the initial value of $S(\Theta)$ can be determined by Eq. (49).

$$
\begin{aligned}
S(0) & =S_{\mathrm{O}}(0)-\left(M_{\mathrm{O}} / M_{\mathrm{C}}\right) S_{\mathrm{C}}(0) \\
& =\beta W\left\{\left(C_{0}^{e}-C_{i, 0}\right)-\left(M_{\mathrm{O}} / M_{\mathrm{C}}\right)\left(C_{\mathrm{C}}^{e}-C_{i, \mathrm{C}}\right)\right\}
\end{aligned}
$$

In the numerical computations, the values of $I$ and $S(0)$ instead of $\beta$ have been adopted as the adjustable parameter, and the transitional variations in the concentrations of oxygen and carbon are calculated, and are shown in Fig. 10 as compared with the empirical data obtained by Mori et al. ${ }^{12)}$ The behavior of the 


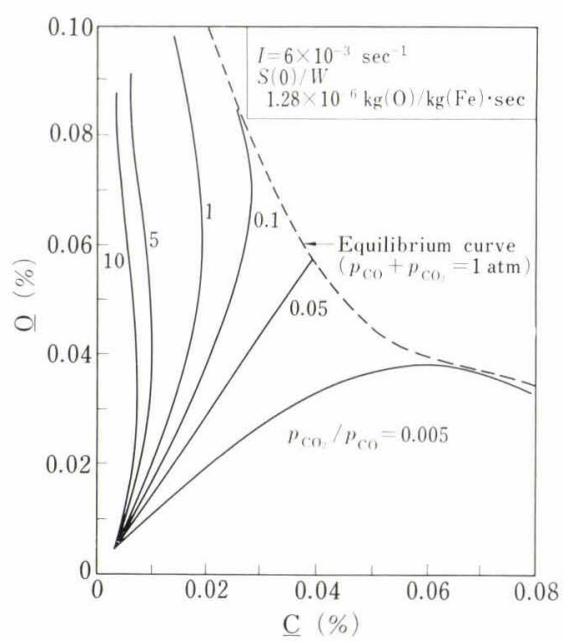

Fig. 11. Relations between the carbon concentration and the oxygen concentration obtained by the use of the model under the various values of the ratio of $p_{\mathrm{CO}}$ to $p_{\mathrm{CO}}$

carbon concentration which increases at first and then decreases, may be seen from Fig. 10. Furthermore, the calculated results concerning the relations between the concentrations of oxygen and carbon under the various ratios of partial pressure, $\left(p_{\mathrm{CO} 2} / p_{\mathrm{CO}}\right)$, are illustrated in Fig. 11, and these results are almost in agreement with the results reported by them. ${ }^{12}$ )

\section{Quantitative Analysis on the Refining Process in LD Converter}

\section{Differences in the Proceeding Sequence of Oxidations}

In regard to the refining processes in LD converter and those in crucible, it has been well known that there exist some differences in the proceeding sequence between the oxidations of silicon or of manganese and the decarburization, and such differences have been explained qualitatively in the foregoing chapter II. In order to explain the differences quantitatively, the effects of the temperature of molten steel on the transitional variations of the concentrations of carbon and silicon have been evaluated from Eqs. (20), (21) and (22) for the constant conditions except temperature, and the calculated results are shown in Fig. 12.

In Fig. 12, the results calculated for the refining process in crucible which is kept at $1600^{\circ} \mathrm{C}$ during the blowihg time are shown by a dot-and-dash line. On the other hand, the results calculated for the blowing process in LD converter under the conditions that the temperature is increased from $1200^{\circ}$ to $1600^{\circ} \mathrm{C}$ linearly with respect to the blowing time are given by a solid line.

In the case represented by the dot-and-dash line, first of all the decarburization takes place and then the oxidation of silicon proceeds in the region of low carbon concentration. On the other hand, in the case represented by the solid line, first of all the oxidation of silicon takes place and in succession the decarburization occurs. Characteristics of the transitional pattern of decarburization in LD converter such

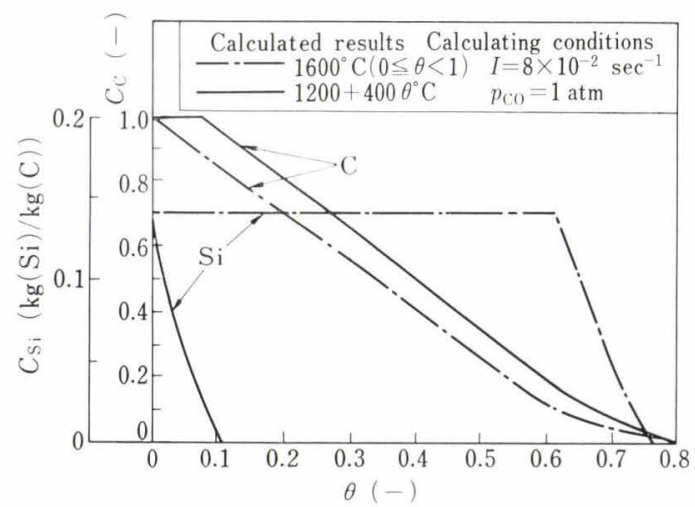

Fig. 12. Effects of the temperature of molten steel on the transitional variations in the concentrations of carbon and of silicon

as the 1st, 2nd and 3rd periods are shown clearly by the solid line of the carbon concentration.

\section{Transitional Variations in Disturbance of Concentra- tion}

The behaviors of the concentrations of $j$-component in molten steel accompanied with the fluctuations of these concentrations which may be caused by the changes of the operating conditions during the blowing process in LD converter are investigated theoretically in this section.

On the basis of the mathematical model proposed previously, the behaviors of the temperature and the concentration of molten steel in the bath of LD converter were calculated by the authors ${ }^{13}$ ) under the conditions with the disturbance of the temperature or the carbon concentration. From these calculated results, it was found that the scrap fed into the bath had the effect compensating disturbances of the temperature and the concentration of molten steel. Namely, it was shown that the trajectory of the point $\left(C_{\mathrm{C}}, T\right)$ on $T-C$ diagram (i.e., graph of $\left.C_{\mathrm{C}} v s . T\right)$ in the case whereat the disturbance was added approached gradually to the trajectory in the case of nondisturbance.

Now, considering that the variations in the concentrations of components in molten steel take place in accordance with Eqs. (15) to (18), the transitional variations of the concentrations in the case that the minute fluctuations, $\delta c_{j}(j=1 \sim n)$, have been added to $c_{j}(j=1 \sim n)$ can be expressed by Eqs. (50) and (51).

$$
\begin{aligned}
& d\left(c_{1}+\delta c_{1}\right) / d \theta=A\left(c_{1}^{*}-c_{1}-\delta c_{1}\right)+B \quad \ldots \ldots \ldots \ldots \\
& d\left(c_{j}+\delta c_{j}\right) / d \theta=A\left(c_{j}^{*}-c_{j}-\delta c_{j}\right) \quad(j=2 \sim n)
\end{aligned}
$$

Subtracting Eqs. (17) and (18) from Eqs. (50) and (51), respectively, Eq. (52) is obtained.

$$
d\left(\delta c_{j}\right) / d \theta=-A \cdot \delta c_{j} \quad(j=1 \sim n)
$$

Denoting the magnitude of fluctuation by $\delta c_{d, j}$ and integrating Eq. (52) with respect $\theta$, Eq. (53) is derived.

$$
\delta c_{j}=\delta c_{d, j} \cdot \exp (-A \theta) \quad(j=1 \sim n) .
$$

Denoting the distance between the trajectory of the concentration change in the space representing the state of the system in the case that the fluctuation has 
been added and the trajectory for non-fluctuation by $l, l$ can be expressed by Eq. (54).

$$
l=\left(\sum_{j=1}^{n} \delta c_{j}^{2}\right)^{1 / 2}=\left(\sum_{j=1}^{n} \delta c_{d, j}^{2}\right)^{1 / 2} \cdot \exp (-A \theta) \ldots \ldots
$$

The right hand side of Eq. (54) represents the function which decreases monotonously, and the value of $l$ becomes equal to 0 as $\theta$ approaches to $\infty$. That is, it may be seen from Eq. (54) that the trajectory of the transitional variations in the concentration is modified to the direction compensating the fluctuation added to the system, even if any magnitude of fluctuation were added at any blowing time.

\section{Conclusion}

In regard to the oxidation of molten steel taking place in the various refining processes, a simplified mathematical model has been developed by taking account of the two kinds of driving forces. On the basis of the model proposed in this paper, the effects of the feeding rate of oxygen and the degree of mixing of molten steel on the transitional variations of process variables in the refining process have been investigated theoretically.

Namely, the differences of oxygen level existing among the experimental results for open hearth, LD converter and crucible obtained by the other investigators have been explained qualitatively, and the experimental results obtained by the other investigators in connection with the oxidations of molten steel in crucible have been quantitatively explained.

It is well known from the comparison between the results observed in LD converter and those in crucible that there exists a difference in the proceeding sequence of the oxidation of silicon and the decarburization, and such a difference has been explained quantitatively with this model.

Furthermore, it has been shown that the model can also be applied successfully to the analysis relevant to the other reactions such that the chemical reaction becomes the rate-controlling step.

\section{Nomenclature}

$A$ : dimensionless factor $=I \Theta_{t}=U_{j} \Theta_{t} / W \quad(-)$

$a_{j}$ : activity of $j$-component (-)

$B: \quad$ factor $=S \Theta_{\imath} / W C_{i, \mathrm{C}}(\mathrm{kg}(\mathrm{O}) / \mathrm{kg}(\mathrm{C}))$

$C_{j}$ : concentration of $j$-component $(\%),(\mathrm{kg}$ $(j) / \mathrm{kg}(\mathrm{Fe}))$

$c_{j}$ : concentration of $j$-component $=C_{j} / C_{i, C}$ $(\operatorname{kg}(j) /(\operatorname{kg}(\mathrm{C}))$

$F_{j}$ : function shown in Eq. (5)

$f_{j}$ : function shown in Eq. (16)

$I$ : mass transport factor $(1 / \mathrm{sec})$

$K(T)$ : equilibrium constant defined by Eq. (2) $\left(\mathrm{atm} \cdot \mathrm{kg}(\mathrm{Fe})^{2} / \mathrm{kg}(\mathrm{O}) \cdot \mathrm{kg}(\mathrm{C})\right)$

$M_{j}$ : molecular mass of $j$-component $(\operatorname{kg}(j) /$ $\operatorname{kgmol}(j))$

$\mathcal{N}_{j}$ : overall rate of mass transfer $(\mathrm{kg}(j) / \mathrm{sec})$

$n_{j, k}$ : rate of mass transfer of $j$-component in $k$ th $\operatorname{step}(\mathrm{kg}(j) / \mathrm{sec})$

$p_{j}$ : partial pressure of $j$-component (atm)

$R_{j, k}$ : resistance to the transfer of $j$-component in $k$-th step $\quad(\mathrm{sec} / \mathrm{kg}(\mathrm{Fe}))$

$S$ : feeding rate of available oxygen $(\mathrm{kg}(\mathrm{O}) /$ $\mathrm{sec})$

$S_{\mathrm{C}}$ : feeding rate of carbon $(\mathrm{kg}(\mathrm{C}) / \mathrm{sec})$

$S_{0}$ : feeding rate of oxygen $(\mathrm{kg}(\mathrm{O}) / \mathrm{sec})$

$T$ : temperature of molten steel $\left({ }^{\circ} \mathrm{K}\right)$

$t: \quad$ dimensionless temperature $=T / T_{i} \quad(-)$

$U_{j}$ : rate constant of over-all reaction $(\mathrm{kg}(\mathrm{Fe}) /$ sec)

$W:$ mass of molten steel $(\mathrm{kg}(\mathrm{Fe}))$

$\alpha_{j}:$ stoichiometric coefficient $(-)$

$\beta$ : proportional constant given in Eqs. (47) and (48) (-)

$\Theta_{\ell}$ : total blowing time $(\mathrm{min})$

$\Theta:$ elapsed time (sec)

Suffix

0: dimensionless elapsed time $=\Theta / \Theta_{t} \quad(-)$

1: oxygen, $i$ : initial value, * equilibrium state

\section{REFERENCES}

1) S. Tamamoto, T. Ikida, and K. Marukawa: Tetsu-to-Hagané, 54 (1968), 381.

2) K. Moriand H. Nomura: Tetsu-to-Hagané, 55 (1970), S460.

3) F. I. Bashliy, V. P. Luegin, V. I. Yavoyskiy, M. F. Panin, and G. S. Kolganov: Izv. VUZov, Cher. Met., (1970), No. 3,32 .

4) M. P. Kvitko, K. A. Blinov, Yu. V. Filatov, V. N. Ustyuzhamin, and L.S. Nechaev: Stal in English, (1970), No. 6, 428.

5) S. Watanabe, H. Yamaguchi, M. Tezuka, and M. Ichinoe: Tetsu-to-Hagané, 57 (1971), S259.

6) H. Nemoto, T. Kawawa, N. Sakata, and M. Okubo: Nippon Kokan Technical Report, $\mathbf{5 0}$ (1970), 21.

7) Y. Kawai and K. Mori: Tetsu-to-Hagané, 56 (1970), 695.

8) Japan Society for the Promotion of Science, 19th Committee: Recommended Values of Equilibrium Constants for the Reaction in Steelmaking, (1968), 40, 2, 73, 112, Nikkan Kogyo Shinbun.

9) Y. Niiri, K. Ito, and K. Sano: Tetsu-to-Hagané, 55 (1969), 437.

10) K. P. Abraham, M. W. Davies, and F. D. Richardson: JISI, 194 (1960), 9, 82.

11) H. Sakao, K. Ito, and T. Kanakubo: Tetsu-to-Hagané, 57 (1971), S436.

12) K. Mori, H. Asai, H. Nomura, and K. Suzuki: Tetsu-toHagané, 57 (1971), S55.

13) S. Asai and I. Muchi: Trans. ISIJ, 11 (1971), 107. 